\title{
Early signs of pneumoconiosis in a dental technician in Italy: a case report
}

\author{
Mara Maria Tiraboschi ${ }^{1}$, Emma Sala ${ }^{2}$, Matteo Ferroni ${ }^{3,4}$, Andrea Tironi ${ }^{5}$, Andrea Borghesi ${ }^{6}$, Maria Enrica Gilberti ${ }^{2}$, \\ Paolo Ceruti ${ }^{7}$, Emanuele Sansone ${ }^{1}$ and Giuseppe De Palma ${ }^{1,2^{*}}$ (D)
}

\begin{abstract}
Background: Dental technicians are at high risk of pneumoconiosis, usually driven by inhalation of mixed dusts, including metals. An etiological diagnosis is not easy to be performed, particularly in advanced stages.

Case presentation: We describe the case of an early pneumoconiosis occurring in a 47-year-old dental technician who developed respiratory symptoms shortly after beginning work. She described the work environment as dusty and lacking relevant primary prevention tools. A chest CT showed multiple peripheral pseudonodular lesions in both lower lobes; bronchoalveolar lavage and bronchial aspirate evidenced numerous macrophages with reflective metal bodies included into the cytoplasm, that at scanning electron microscopy coupled to Energy Dispersive X-Ray Analysis resulted Zirconium and Aluminum, whereas Tungsten (W) was localized outside cells. End of shift urinary concentrations of W were substantially raised as compared to pre-shift (1.1 vs. $0.2 \mu \mathrm{g} / \mathrm{L})$.
\end{abstract}

Conclusions: We concluded for diagnosis of early work-related pneumoconiosis due to abnormal occupational exposure to metals. The case demonstrates the need also for dental professionals to comply with industrial hygiene standards and to be monitored by occupational health physicians.

Keywords: Dental technician, Metals, Pneumoconiosis, Occupational disease, Case report

\section{Background}

Dental technicians are exposed to pneumotoxic elements, including crystalline silica and hard metal alloys that can lead to pneumoconiosis [1-4]. Recently, a cluster of 9 cases of idiopathic pulmonary fibrosis (IPF) among dentists and other dental professionals has been reported [5]. An etiological diagnosis is not easy to be performed, particularly if formulated at an advanced stage. We describe an early pneumoconiosis occurring in a dental technician who developed early respiratory symptoms shortly after beginning work.

\footnotetext{
*Correspondence: giuseppe.depalma@unibs.it

${ }^{1}$ Department of Medical and Surgical Specialties, Radiological Sciences, and Public Health, Unit of Occupational Health and Industrial Hygiene, University of Brescia, Brescia, Italy

Full list of author information is available at the end of the article
}

\section{Case presentation}

On 27th July 2020, a 47-year-old woman, working as a ceramic dental technician since November 2018, required a medical examination at our Occupational Health Dept., as in the previous months she was affected by dry and irritating cough, especially related to intense work activity. She also suffered some episodes of lowgrade fever and fatigue and dyspnea on efforts. In March 2020, chest CT showed lung nodules characterized by net margins and oval shape, in peripheral or subpleural site, especially in the inferior lobes. The biggest nodule, 9 $\mathrm{mm}$, with polygonal shape, was in the anterior basal segment of the righ inferior lobe (Fig.1).

Pulmonary function tests were in the normality range and revealed a normal diffusing capacity, albeit at the lower limits of the normal (DLCO/VA 73\%); autoimmunity markers were in the normal range. Then, she underwent fibro-bronchoscopy with bronchoalveolar lavage 


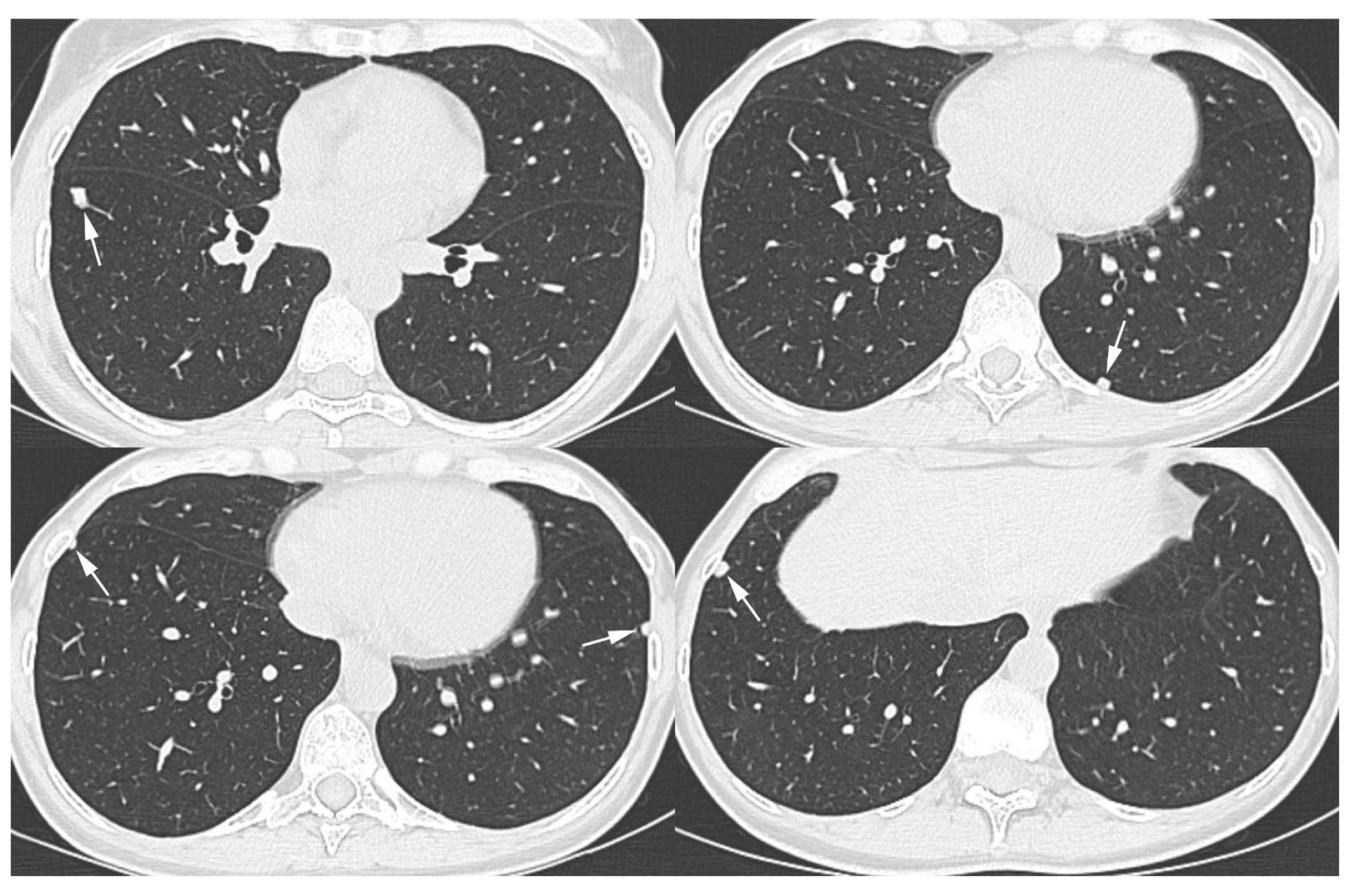

Fig. 1 Axial thin-section CT images with lung window setting show multiple peripheral pulmonary nodules (arrows) in both lower lobes

(BAL) and bronchial aspirate (BAS). BAL differential cell count showed macrophages (79\%), lymphocytes (18\%), neutrophil granulocytes (3\%), and a CD4/CD8 lymphocyte ratio of 7.8. In both BAL and BAS, several macrophages with numerous intracytoplasmic exogenous metallic material and reflective dust were seen at optical microscopy. Owing to the SARS-CoV2 pandemic, she was absent from workplace from March to August 2020 and in such period her symptoms ameliorated. At work, the woman was involved in milling and polishing monolithic zirconia structures, then layered with ceramic. She described workplace as dusty, lacking aspiration hoods hence she was concerned about workplace safety. She used respiratory personal protective equipment (PPE) inconstantly.

We examined three samples of dust settled nearby her workstation by inductively coupled mass spectrometry (ICP-MS) [6]. Among others, we detected average Cobalt (Co), Tungsten (W), Zirconium (Zr) and Yttrium $(\mathrm{Y})$, a component of dental ceramic) at concentrations of 45, 60, 96 and $176 \mu \mathrm{g} / \mathrm{g}$, respectively. Apart from Co, the same elements could be detected, always by ICP-MS, on a paraffin-embedded BAS sample. On BAL cytocentrifugated slides, scanning electron microscopy (SEM) coupled to Energy Dispersive X-Ray Analysis (EDX) showed numerous inorganic particles, containing $\mathrm{Zr}$ and Aluminum ( $\mathrm{Al})$, the latter probably as oxide, within the macrophages (Figs. 2, 3). In addition, a signal attributed

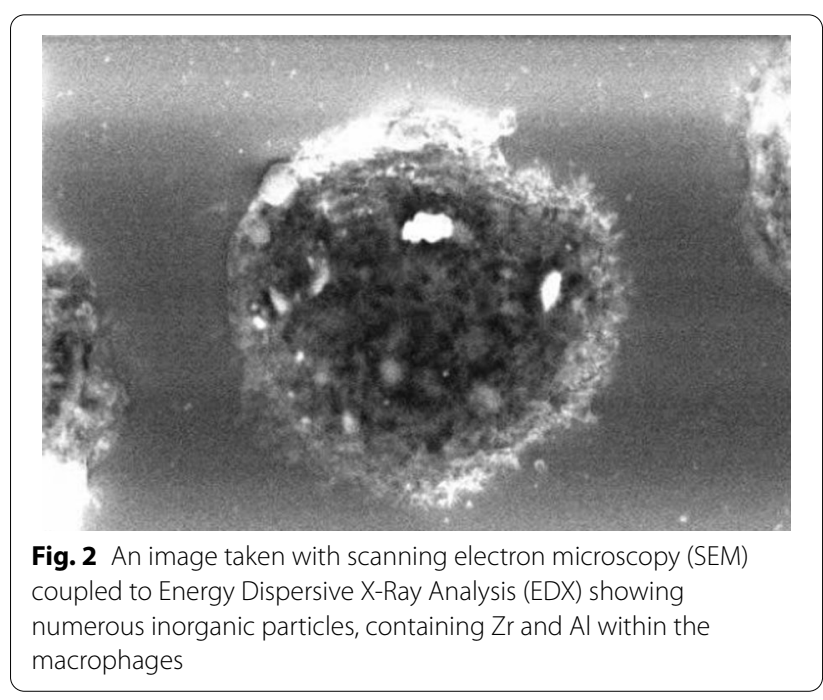

to $\mathrm{W}$ was detected but not localized in a specific image detail. About a month after return at work, we investigated metal concentrations in urine $(\mathrm{U})$ and in exhaled breath condensate $(\mathrm{EBC})$, collected either at the beginning and at the end of a workweek, by ICP-MS. We could demonstrate a 6 times weekly increase of urinary concentrations of W $(0.18 \mu \mathrm{g} / \mathrm{L}$ vs. $1.1 \mu \mathrm{g} / \mathrm{L})$. We concluded for a diagnosis of early work-related pneumoconiosis due to abnormal occupational exposure to metals. We advised 


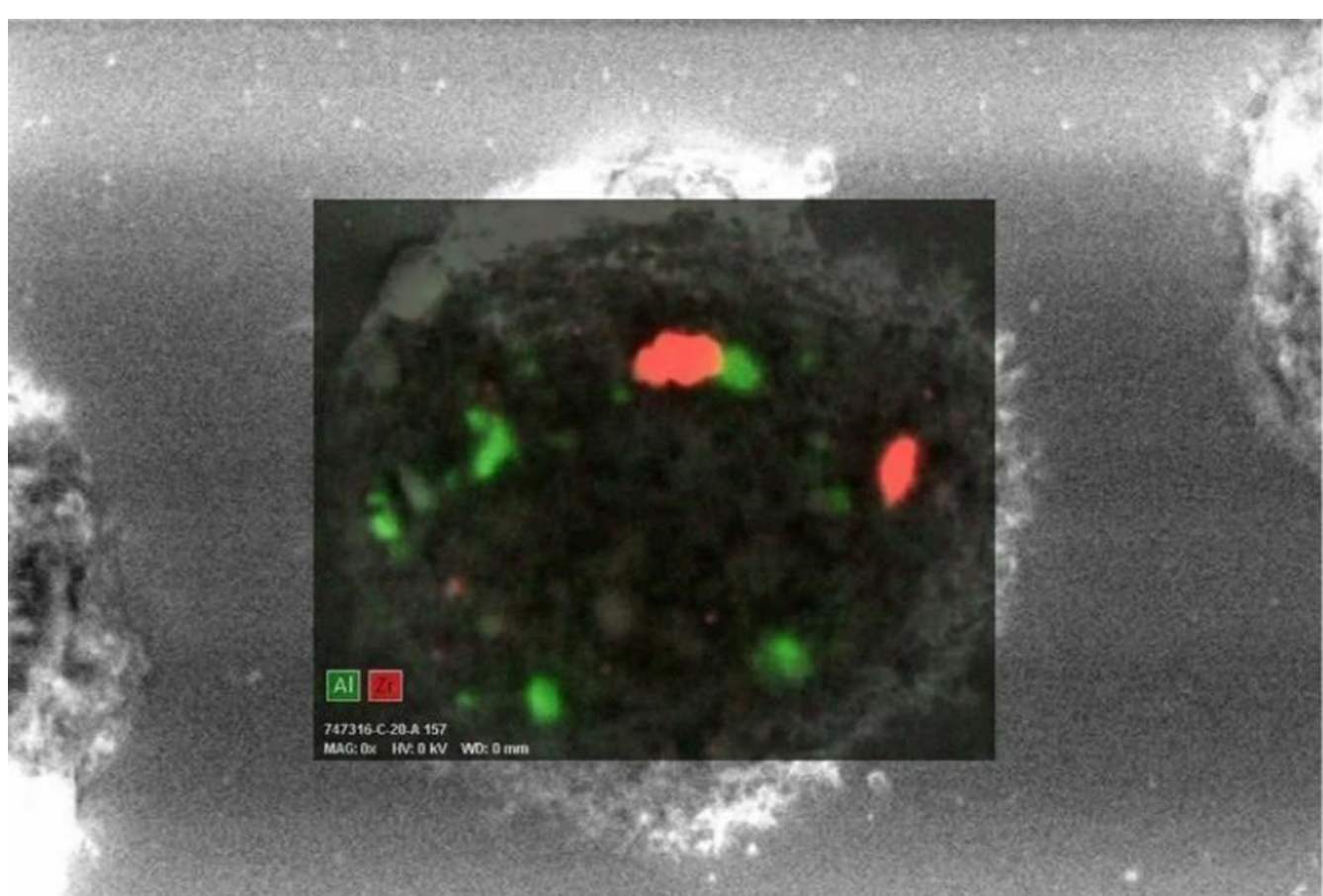

Fig. 3 A detail of the previous image: the green areas show the zones with the biggest concentration of Al, the red areas are the ones with the major concentration of $\mathrm{Zr}$

periodical chest $\mathrm{CT}$ and pulmonologist monitoring (the next after 6 months), along with the prescription to strictly wear respiratory personal protective equipment (PPE) at work.

\section{Discussion and conclusions}

Dental technicians are at high risk of pneumoconiosis (prevalence rate 4.5-23.6\% after a mean exposure duration of $12.8-28.4$ years) $[4,7-10,15]$, usually driven by inhalation of mixed dusts, including crystalline silica and hard metals, mostly chromium-cobalt-molybdenum alloys $[3,11,12]$.

Usually, diagnosis is formulated after several years of exposure. The CT or RX patterns consist of micronodular and reticular lesions usually in upper-middle lung lobes and restrictive and/or obstructive lung function impairment [13-15]. Our case developed pulmonary symptoms early after work beginning. According to occupational history and analytical results, she was heavily exposed to mixed dusts, including $\mathrm{W}, \mathrm{Al}$ oxide and $\mathrm{Zr}$, both the latter known to be pneumotoxic [16-18]. $\mathrm{Al}$ oxide can elicit sarcoid-like or berylliosis-like lung granulomatosis, accompanied by T-helper lymphocyte alveolitis [19], whereas Zr can induce a "benign" pneumoconiosis with little or no fibrosis [16]. W alone is not toxic but, if associated to $\mathrm{Co}$, it may give rise to the very insidious hard metal lung disease [20]. In such event, Co is very soluble and hence often its detection in lung tissue samples fails. In the presented case, the high exposure levels to mixed metal dusts, coupled to some yet unrecognized individual susceptibility trait, may have determined the accelerated development of lung damage. A main limitation affecting our diagnostic potential was the unavailability of lung tissue. In conclusion, the case demonstrates that dental technicians are at risk of developing lung disease. Prevention in such work sector implies careful risk assessment through airborne and biological monitoring of pneumotoxic metals.

\section{Abbreviations}

Al: Aluminum; BAL: Bronchoalveolar lavage; BAS: Bronchial aspirate; Co: Cobalt; EBC: Exhaled breath condensate; EDX: Energy Dispersive X-Ray Analysis; ICPMS: Inductively coupled mass spectrometry; IPF: Idiopatic pulmonary fibrosis; PPE: Personal protective equipment; SEM: Scanning electron microscopy; U: Urine; W: Tungsten; Y: Yttrium; Zr: Zirconium.

\section{Acknowledgements}

Not appliable.

\section{Authors' contributions}

M.M.T. contributed to the collection of the medical history, to the medical examination, to the analysis and interpretation of data and to the drafting of the article. E.S. contributed to the collection of the medical history, to the analysis and interpretation of the data and to the drafting of the article. M.F. carried out the analysis in electron microscopy. A.T. contributed to the analysis of the pathological data and contributed to the drafting of the article. A.B. analyzed the radiological data and contributed to the drafting of the article. M.E.G. carried out ICP-MS analyses. P.C. carried out specialist pneumological 
evaluation and contributed to the drafting of the article. E.S. contributed to the analysis and interpretation of the data and to the drafting of the article. G.D.P. brought the greatest contribution in the analysis and interpretation of the data and in the drafting of the article. All authors read and approved the final manuscript.

\section{Funding}

The authors declare no funding was required for the writing and submission of the manuscript.

\section{Availability of data and materials}

Data sharing is not applicable to this article as no datasets were generated or analyzed during the current study.

\section{Declarations}

\section{Ethics approval and consent to participate}

Not applicable.

\section{Consent for publication}

Informed written consent was received from the patient for publication of the manuscript.

\section{Competing interests}

The authors declare that they have no competing interests.

\section{Author details}

'Department of Medical and Surgical Specialties, Radiological Sciences, and Public Health, Unit of Occupational Health and Industrial Hygiene, University of Brescia, Brescia, Italy. ${ }^{2}$ Occupational Health, Occupational Hygiene, Toxicology and Prevention Unit, University Hospital "Spedali Civili Di Brescia", Brescia, Italy. ${ }^{3}$ CNR-Institute of Microelectronics and Microsystems, Bologna, Italy. ${ }^{4}$ Department of Civil, Environmental, Architectural Engineering and Mathematics, University of Brescia, Brescia, Italy. ${ }^{5}$ Pathology Department, University Hospital "Spedali Civili Di Brescia”, Brescia, Italy. ${ }^{6}$ Department of Medical and Surgical Specialties, Radiological Sciences, and Public Health, Unit of Radiological Sciences, University of Brescia, Brescia, Italy. ${ }^{7}$ Pulmonology Department, University Hospital "Spedali Civili Di Brescia", Brescia, Italy.

Received: 4 March 2021 Accepted: 28 October 2021

Published online: 07 November 2021

\section{References}

1. Ergün D, Ergün $R$, et al. Pneumoconiosis and respiratory problems in dental laboratory technicians: analysis of 893 dental technicians. Int J Occup Med Environ Health. 2014;27:785-96.

2. Hirano T, Numakura T. The first case of multiple pulmonary granulomas with amyloid deposition in a dental technician; a rare manifestation as an occupational lung disease. BMC Pulm Med. 2018;18(1):77.
3. Ardekani A, Ayatollahi J, Ayatollahi F, Bahrololoomi R, Ayatollahi J, Ayatollahi A, et al. Occupational hazards to dental staff. Dent Res J (Isfahan). 2012;9:2-7.

4. Torbica N, Krstev S. World at work: dental laboratory technicians. Occup Environ Med. 2006;63:145-8.

5. Nett RJ, Cummings KJ, Cannon B, Cox-Ganser J, Nathan SD. Dental personnel treated for idiopathic pulmonary fibrosis at a Tertiary Care Center-Virginia, 2000-2015. MMWR. 2018;67(9):270-3.

6. De Palma G, Catalani S, et al. Lack of correlation between metallic elements analyzed in hair by ICP-MS and autism. J Autism Dev Disord. 2012;42(3):342-53.

7. Centers for Disease Control and Prevention (CDC). Silicosis in dental laboratory technicians-five states, 1994-2000. MMWR Morb Mortal Wkly Rep. 2004:53:195-7.

8. Kartaloglu Z, Ilvan A, Aydilek R, et al. Dental technician's pneumoconiosis: mineralogical analysis of two cases. Yonsei Med J. 2003:44:169-73.

9. Froudarakis ME, Voloudaki A, Bouros D, et al. Pneumoconiosis among Cretan dental technicians. Respiration. 1999;66:338-42.

10. Selden A, Sahle W, Johansson L, et al. Three cases of dental technician's pneumoconiosis related to cobalt- chromium-molybdenum dust exposure. Chest. 1996;109:837-42.

11. Nett RJ, et al. Dental personnel treated for idiopathic pulmonary fibrosis at a tertiary care center-Virginia, 2000-2015. Morb Mortal Wkly Rep. 2018:67(9):270-3.

12. Nayebzadeh A, Dufresne A, Harvie S, et al. Mineralogy of lung tissue in dental laboratory technicians' pneumoconiosis. Am Ind Hyg Assoc J. 1999;60:349-53.

13. Kahraman $\mathrm{H}$, Koksal N, et al. Pneumoconiosis in dental technicians: HRCT and pulmonary function findings. Occup Med. 2014;64:442-7.

14. Tan $\mathrm{HL}$, et al. Dental technician pneumoconiosis mimicking pulmonary tubercolosis: a case report. BMC Pulm Med. 2016;16:131.

15. Okamoto $M$, Tominaga M. Dental technicians' pneumoconiosis. Intern Med. 2017;56:3323-6.

16. Nemery B. Metal toxicity and the respiratory tract. Eur Respir J. 1990:3(2):202-19.

17. Newman LS. Metals that cause sarcoidosis. Semin Respir Infect. 1998;13(3):212-20.

18. Blin T, De Muret A, et al. Desquamative interstitial pneumonia induced by metal exposure. A case report and literature review. Sarcoidoses Vasc Diffuse Lung Dis. 2020;37(1):79-84.

19. De Vuyst P, Dumortier P. Sarcoidlike lung granulomatosis induced by aluminum dusts. Am Rev Respir Dis. 1987;135(2):493-7.

20. Futoshi Mizutani R, Terra-Filho M. Hard metal lung disease: a case series. J Bras Pneumol. 2016;42(6):447-52.

\section{Publisher's Note}

Springer Nature remains neutral with regard to jurisdictional claims in published maps and institutional affiliations.

Ready to submit your research? Choose BMC and benefit from:

- fast, convenient online submission

- thorough peer review by experienced researchers in your field

- rapid publication on acceptance

- support for research data, including large and complex data types

- gold Open Access which fosters wider collaboration and increased citations

- maximum visibility for your research: over $100 \mathrm{M}$ website views per year

At BMC, research is always in progress.

Learn more biomedcentral.com/submissions 